\title{
Distribution and viability of fetal and adult human bone marrow stromal cells in a biaxial rotating vessel bioreactor after seeding on polymeric 3D additive manufactured scaffolds
}

\section{OPEN ACCESS}

Edited by:

Alessandro Polini, Radboud University Medical Centre,

Netherlands

Reviewed by:

Y. Shrike Zhang,

Harvard Medical School, USA

Ljupcho Prodanov,

Nottingham University, UK

*Correspondence:

Lorenzo Moron

I.moroni@maastrichtuniversity.nl

Specialty section:

This article was submitted to Tissue Engineering and Regenerative Medicine, a section of the journal Frontiers in Bioengineering and Biotechnology

Received: 30 July 2015 Accepted: 08 October 2015 Published: 23 October 2015

Citation:

Leferink AM, Chng Y-C, van Blitterswijk CA and Moroni L (2015) Distribution and viability of fetal and adult human bone marrow stromal cells in a biaxial rotating vessel bioreactor after seeding on polymeric $3 D$ additive manufactured scaffolds.

Front. Bioeng. Biotechnol. 3:169. doi: 10.3389/fbioe.2015.00169

\author{
Anne M. Leferink ${ }^{1,2}$, Yhee-Cheng Chng ${ }^{3}$, Clemens A. van Blitterswijk ${ }^{1,2}$ and \\ Lorenzo Moroni, ${ }^{1,2 *}$
}

${ }^{1}$ Department of Tissue Regeneration, MIRA Institute, University of Twente, Enschede, Netherlands, ${ }^{2}$ Department of Complex Tissue Regeneration, Faculty of Health, Medicine and Life Sciences, Maastricht University, Maastricht, Netherlands, ${ }^{3}$ Quintech Life Sciences Pte Ltd., Singapore, Singapore

One of the conventional approaches in tissue engineering is the use of scaffolds in combination with cells to obtain mechanically stable tissue constructs in vitro prior to implantation. Additive manufacturing by fused deposition modeling is a widely used technique to produce porous scaffolds with defined pore network, geometry, and therewith defined mechanical properties. Bone marrow-derived mesenchymal stromal cells (MSCs) are promising candidates for tissue engineering-based cell therapies due to their multipotent character. One of the hurdles to overcome when combining additive manufactured scaffolds with MSCs is the resulting heterogeneous cell distribution and limited cell proliferation capacity. In this study, we show that the use of a biaxial rotating bioreactor, after static culture of human fetal MSCs (hfMSCs) seeded on synthetic polymeric scaffolds, improved the homogeneity of cell and extracellular matrix distribution and increased the total cell number. Furthermore, we show that the relative mRNA expression levels of indicators for stemness and differentiation are not significantly changed upon this bioreactor culture, whereas static culture shows variations of several indicators for stemness and differentiation. The biaxial rotating bioreactor presented here offers a homogeneous distribution of hfMSCs, enabling studies on MSCs fate in additive manufactured scaffolds without inducing undesired differentiation.

Keywords: bone marrow stromal cells, scaffolds, biaxial rotating bioreactor, perfusion-flow bioreactor, cellular distribution

\section{INTRODUCTION}

The field of tissue engineering aims at applying the fundamentals of cell biology and materials engineering to construct replacements for damaged, diseased, or lost tissue (Langer and Vacanti, 1993). One of the conventional approaches is based on three-dimensional (3D) mechanically stable scaffolds in combination with multipotent cell types. Scaffolds with a highly defined 
geometry, porosity, and tailored mechanical properties can be obtained by additive manufacturing (Moroni et al., 2005). These scaffolds provide the necessary support for cells to attach, proliferate, and differentiate, and define the overall shape of the tissue engineered transplant. Several researchers already showed successful application of such scaffolds in, for example, bone and cartilage tissue engineering in vivo (Woodfield et al., 2004; Kim et al., 2012; Reichert et al., 2012). Woodfield et al. found a rapid attachment and a homogenous distribution of both bovine and human chondrocytes on poly (ethylene oxide terephthalate)-co-poly (butylene terephthalate) (PEOT/PBT) based scaffolds after spinner flask culture in vitro. Subsequently, scaffolds seeded with bovine chondrocytes were implanted subcutaneously in mice for 21 days and formed cartilaginous tissue in vivo as demonstrated by the presence of articular extracellular matrix (ECM) components (Woodfield et al., 2004). Despite successes in regenerating tissues with additive manufactured scaffolds optionally combined with different bioreactors, the highly organized open structure of such scaffolds poses still challenges in homogenously distributing cells and controlling their proliferation and differentiation capacities. This is even more important when mesenchymal stromal cell (MSCs) are used, as their capacity to adhere and be homogeneously distributed in 3D scaffolds has shown to be more demanding (Griffon et al., 2011).

To gain control over cell seeding efficiency, distribution and fate on additive manufactured $3 \mathrm{D}$ scaffolds in vitro prior to implantation or as a study model, several hurdles have to be overcome. First, the cell seeding process has to be optimized per scaffold geometry, scaffold material, and cell type to achieve proper cell attachment and distribution throughout the construct (Sobral et al., 2011). Several studies showed the influence of scaffold geometry or culture conditions in cell and tissue distribution after in vitro culture (Wang et al., 2005; Leferink et al., 2013). Papadimitropoulos et al. (2013) introduced a collagen-network in porous PCL-TCP scaffolds, which resulted in a 2.5-fold increase in MSCs seeding efficiency under perfusion flow compared to the bare PCL-TCP scaffolds. Despite an increased cell seeding efficiency in the presence of a collagen-network, no obvious qualitative differences were found after 19 days of culture among the experimental groups with respect to cell viability and distribution, and ECM formation. Although the incorporation of a collagenous matrix in additive manufactured scaffolds seemed to have a beneficial effect on cell seeding efficiency, control over cell fate remains to be further elucidated.

A second hurdle to overcome is the supply of oxygen and nutrients as well as the clearance of metabolic products which showed to become critically limiting for cells cultured under static conditions (Schantz et al., 2012). Bioreactor systems, based on convection, such as rotating vessels and stirrer flasks, or based on perfusion, such as a directional flow-through bioreactor, are used to overcome these mass transfer limitations (Grayson et al., 2011). These systems do not only enhance nutrient and waste product exchange but can also exert mechanical stimuli on the cells to proliferate, migrate, or differentiate (Martin et al., 2004; Grayson et al., 2011). Although most of these commercially available rotating vessel bioreactors are uniaxial in design, Singh et al. (2005) have shown with in silico simulations that a biaxial design, which rotates simultaneously in two independent orthogonal axes, resulted in improved fluidics over an uniaxial design. Therefore, we investigated the use of a biaxial bioreactor system for the in vitro culture of highly porous PEOT/PBT scaffolds seeded with human fetal MSCs (hfMSCs) or human adult MSCs (haMSCs).

Previous work showed the differentiation potential of hfMSCs into the adipogenic (Jo et al., 2008), osteogenic (Guillot et al., 2008; Abarrategi et al., 2012; Brady et al., 2014), and chondrogenic (Abarrategi et al., 2012; van Gool et al., 2012) lineages and maintenance of telomerase activity during in vitro monolayer culture (Jo et al., 2008). Also for haMSCs, multipotency is traditionally shown by studying the differentiation capacity into the adipogenic (Pittenger et al., 1999), chondrogenic (Mackay et al., 1998; Pittenger et al., 1999), and osteogenic (Pittenger et al., 1999) lineages in the presence of soluble factors in monolayer or pellet culture in vitro. Yet, the differentiation of haMSCs into multiple other lineages, such as the neurogenic (Zaim et al., 2012), endothelial (Janeczek Portalska et al., 2012), and myogenic lineages (Muguruma et al., 2003; Bossolasco et al., 2004), has been reported as well. The multipotent differentiation capacity of haMSCs is donor and age dependent and decreases upon increasing population doublings in vitro (Zaim et al., 2012). Zhang et al. (2009a) reported a superior proliferative and osteogenic differentiation capacity of hfMSCs over haMSCs after comparative studies in vitro in static monolayer culture. In addition, both hfMSCs and haMSCs showed osteogenic differentiation on a composite bioactive PCL-TCP scaffold in static culture in vitro and ectopic bone formation in the scaffold after implantation in vivo. Yet, osteogenic differentiation of hfMSCs was found superior to haMSCs.

We hypothesize that by the introduction of a biaxial rotating bioreactor, higher cell numbers and a more homogeneous distribution of cells throughout 3D scaffolds could be achieved compared to static culture in a well plate. It is well-known that shear forces due to medium flow can affect cell fate. Therefore, in this study, the effect of bioreactor culture on cell and ECM distribution as well as on cellular phenotype was assessed for both hfMSCs and haMSCs cultured on scaffolds in two different bioreactor systems and compared to the results from static culture on scaffolds in a well plate. In our study, we chose PEOT/ $\mathrm{PBT}$ as a biomaterial to fabricate $3 \mathrm{D}$ additive manufactured scaffolds. This family of copolymers has shown successful applications in tissue regeneration applications (Beumer et al., 1994; Claase et al., 2007; Moroni et al., 2008), due to the flexibility to change their physico-chemical and mechanical properties (Deschamps et al., 2002). These results in the possibility to control cell adhesion, morphology, and ultimately phenotype at the interface with 3D scaffolds made of these biomaterials, which is of particular interest for stem cell-driven tissue regeneration strategies. 


\section{MATERIALS AND METHODS}

\section{Isolation and Culture of hfMSCs and haMSCs}

Bone marrow-derived hfMSCs were isolated as described before, from 17 weeks and 1-day-old fetuses after clinically indicated termination of pregnancy (Chan et al., 2007; Zhang et al., 2009b). Pregnant women gave separate written consent for the clinical procedure and for the use of fetal tissue for research purposes. Briefly, fetal bone marrow cells were retrieved by flushing the bone marrow cells out of the humeri and femurs into Dulbecco's modified eagle's medium (DMEM, Sigma, USA) with Glutamax (GIBCO, USA) supplemented with $10 \%$ heat-inactivated fetal bovine serum (FBS, Hyclone, USA), $50 \mathrm{U} / \mathrm{mL}$ penicillin, and $50 \mu \mathrm{g} / \mathrm{mL}$ streptomycin (GIBCO, USA), which will be referred to as fMSC medium. Medium was refreshed twice per week and cells were used for further subculturing or cryopreservation on reaching near confluence.

Bone marrow-derived haMSCs (donor 1 female, 77 years old; donor 2 female, 55 years old) were isolated and proliferated, as described previously (de Bruijn et al., 1999). Bone marrow aspirates were obtained from patients who had given written informed consent. Briefly, aspirates were cultured in minimal essential medium (alpha-MEM; Life Technologies, USA) supplemented with $10 \%$ heat-inactivated fetal bovine serum (FBS; Lonza, USA), $0.2 \mathrm{mM}$ L-Ascorbic acid 2-phosphate magnesium salt (ASAP, Sigma-Aldrich, the Netherlands), $2 \mathrm{mM}$ L-glutamine (L-glut, Invitrogen, the Netherlands), $100 \mathrm{U} / \mathrm{mL}$ penicillin (Life Technologies, USA), $100 \mu \mathrm{g} / \mathrm{mL}$ streptomycin (Life Technologies, USA), and $1 \mathrm{ng} / \mathrm{mL}$ basic fibroblast growth factor (bFGF; Instruchemie, The Netherlands), which will be referred to as proliferation medium. Cells were cultured at $37^{\circ} \mathrm{C}$ in a humidified atmosphere with $5 \% \mathrm{CO}_{2}$. Medium was refreshed twice per week and cells were used for further subculturing or cryopreservation on reaching near confluence.

\section{Fabrication of PEOT/PBT Scaffolds}

Scaffold were fabricated of PolyActive ${ }^{\mathrm{TM}}$ 300/55/45 (PolyVation, the Netherlands), a block copolymer is composed of poly(ethylene oxide terephthalate) (PEOT) and poly(butylene terephthalate) (PBT) with a weight ratio of 55:45 for the two components, respectively, and a molecular weight of the starting poly(ethylene glycol) (PEG) segments of $300 \mathrm{Da}$ used in the co-polymerization process (Deschamps et al., 2002). Fused deposition modeling was used with a bioscaffolder (SysENG, Germany) to fabricate 3D cylindrical scaffolds as described before (Moroni et al., 2005), with a diameter of $8 \mathrm{~mm}$ and a height of $3 \mathrm{~mm}$. For the additive manufacturing process, the fiber spacing was set to $1000 \mu \mathrm{m}$, the layer thickness to $150 \mu \mathrm{m}$, and a needle with an internal diameter of approximately $250 \mu \mathrm{m}$ was used, which resulted in fiber diameters of approximately $200 \mu \mathrm{m}$. Scaffolds were treated in Argon plasma for $30 \mathrm{~min}$ with a pressure of $0.1-0.2 \mathrm{mBar}$ and a power of $30 \mathrm{~W}$. Sterilization of all scaffolds was performed in $70 \%$ ethanol twice for $30 \mathrm{~min}$, subsequently washed in PBS first for $5 \mathrm{~min}$ and additionally twice for another $30 \mathrm{~min}$ each time, and finally incubated in culture medium overnight prior to cell culture.

\section{Cell Seeding on PEOT/PBT Scaffolds}

For studies with hfMSCs, scaffolds were transferred from a tube with culture medium to a non-treated 24-well plate (Greiner bioone, Germany). Passage 3 hfMSCs were harvested from monolayer expansion, and seeded on the scaffolds with a density of 750,000 cells in $30 \mu \mathrm{L}$ of fMSC medium. After 15 min of incubation, the scaffolds were flipped and allowed to incubate for another $45 \mathrm{~min}$ before $10 \mu \mathrm{L}$ of fMSC medium was added. Subsequently, for the next $5 \mathrm{~h}, 10 \mu \mathrm{L}$ of proliferation medium was added for each seeded scaffolds at an interval of $75 \mathrm{~min}$ for each addition. Scaffolds were then transferred to a non-treated 24-well plate (Greiner bio-one, Germany) with $750 \mu \mathrm{L}$ of proliferation medium and cultured for 3 days either in static culture conditions or in a biaxial rotating vessel bioreactor for which the culture parameters are specified in the next section.

For studies with haMSCs, scaffolds were transferred from a tube with culture medium to a non-treated 24-well plate (NUNC, Fisher Scientific, the Netherlands). Passage 3 haMSCs were harvested from monolayer expansion, and seeded on the scaffolds with a density of 750,000 cells in $100 \mu \mathrm{L}$ of proliferation medium. After $1.5 \mathrm{~h}$ incubation, the medium was filled up to $1 \mathrm{~mL}$ and cell culture was continued for 3 days in static culture condition before transferring the samples to a new culture well, to the biaxial bioreactor system, or to a bioreactor perfusion culture. The culture parameters in the bioreactors are specified in the next section.

In the results section, the legends of the figures refer to the total culture time, including the static incubation period on the scaffolds placed in a well plate (in most figures this period was 3 days, unless specified differently).

\section{Bioreactor Culture}

After static culture, some of the scaffolds were transferred to the biaxial bioreactor system or the chamber of the perfusion bioreactor, whereas a control group was maintained under static culture conditions (Figure 1). The perfusion bioreactor consisted of a small chamber in which the scaffold was press-fitted to ensure the medium to be flown through the longitudinal pores of the scaffold. The set-up of the perfusion bioreactor was constructed, as described before (Janssen et al., 2006). Medium was ran with a flow speed of $0.1 \mathrm{~mL} / \mathrm{min}$ in a home-made incubator at $37^{\circ} \mathrm{C}$ with a controlled flow of mixed gas containing $5 \% \mathrm{CO}_{2}$ and $21 \% \mathrm{O}_{2}$.

The biaxial bioreactor system consisted of a cylindrical vessel for culture (volume $40 \mathrm{~mL}$ ), in which the cellular-scaffold constructs are mounted to the lid of the bioreactor by pins, and a medium reservoir to ensure continuous replacement of the medium in the culture vessel. Gaseous exchange was enabled through a special membrane incorporated into the medium reservoir. The bioreactor was ran with a medium flow speed of $1 \mathrm{rpm}$ (corresponding to $1.5 \mathrm{~mL} / \mathrm{min}$ ), a biaxial rotation with an arm rotational speed of $2 \mathrm{rpm}$, and a chamber rotation speed of $3 \mathrm{rpm}$ at $37^{\circ} \mathrm{C}$ in a humidified atmosphere with $5 \% \mathrm{CO}_{2}$.

Proliferation medium was used to fill the $40 \mathrm{~mL}$ medium reservoir of the perfusion bioreactor containing 1 scaffold seeded with haMSCs per circuitry. Proliferation medium was used to fill the $40 \mathrm{~mL}$ bioreactor chamber and the $300 \mathrm{~mL}$ reservoir of the 


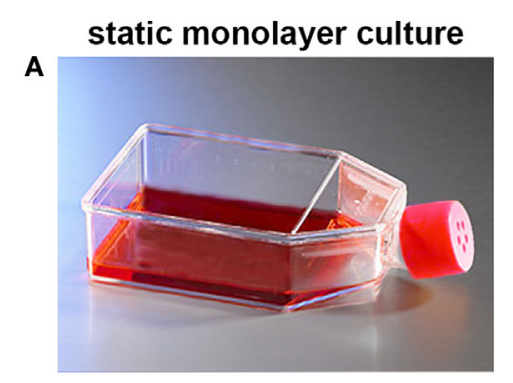

culture in a biaxial bioreactor

C
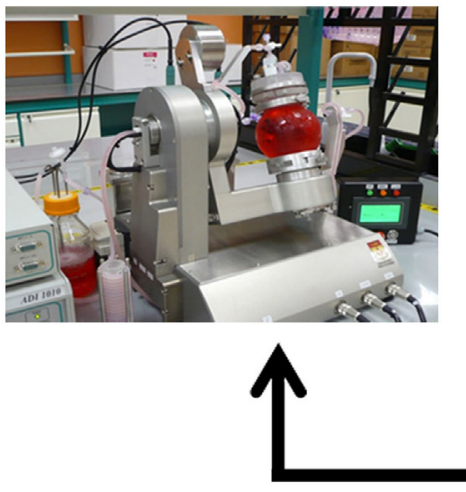

hMSCs are trypsinized from monolayer culture and seeded on scaffolds or stored for PCR analysis (day 0 )

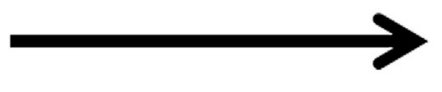

culture in a perfusion bioreactor
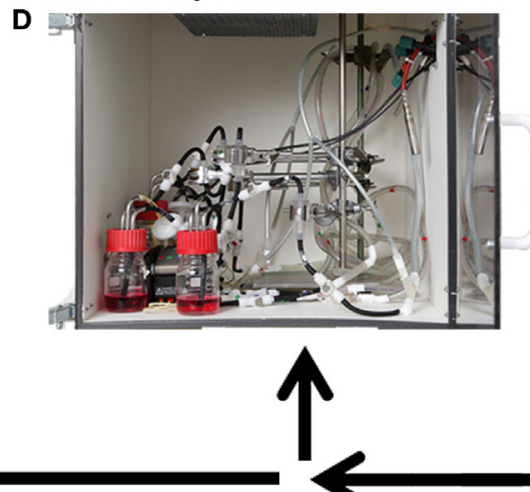

additive manufactured 3D scafolds

B

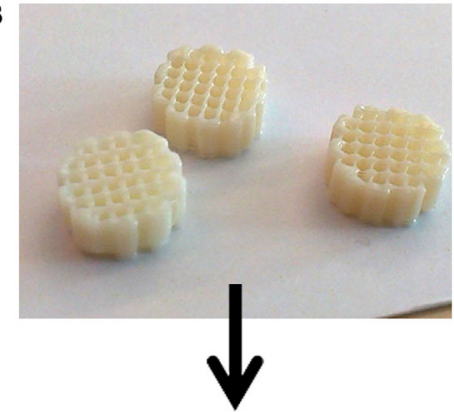

static culture in a well-plate

E

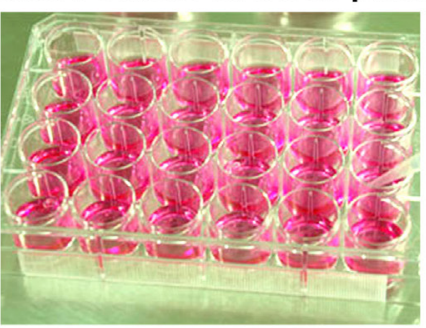

90 minutes or 6 hours of cell adherence before adding medium. Incubation for 3 days

transfer of scaffolds to bioreactors or an additional period of static culture in a well-plate

FIGURE 1 | A schematic representation of the bioreactor set-ups. (A) hMSCs were cultured at $37^{\circ} \mathrm{C}$ in a humidified atmosphere with $5 \% \mathrm{CO} 2$ in culture flasks to allow them to proliferate. After expansion, the cells were trypsinized from monolayer culture and seeded onto 3D additive manufactured scaffolds (B), or stored for analysis of the basal gene expression levels (day 0). (E) Seeded scaffolds were statically incubated for $90 \mathrm{~min}$ or $6 \mathrm{~h}$ in a 24-well plate to allow the hMSCs to adhere to the 3D scaffold before filling the well with culture medium. After several days of incubation, the scaffolds were transferred to a small press-fit chamber in the perfusion bioreactor (D) or in the vessel of the biaxial rotating bioreactor (C) in which culture was prolonged for several days before analyses.

biaxial bioreactor containing 4 scaffolds seeded with haMSCs. fMSC medium was used to fill the $500 \mathrm{~mL}$ bioreactor chamber and the $300 \mathrm{~mL}$ reservoir of the biaxial bioreactor containing 12 scaffolds seeded with hfMSCs. As a control, static culture was continued on the scaffolds that were transferred to a new well in a non-treated 24-well plate.

\section{Viability Staining}

Cell viability was assessed by $4 \mu \mathrm{g} / \mathrm{mL}$ fluorescein diacetate (FDA, Sigma-Aldrich, the Netherlands) and $40 \mu \mathrm{g} / \mathrm{mL}$ propidium iodide (PI, Sigma-Aldrich, the Netherlands) staining, where FDA stains viable cells green, and PI stains necrotic and apoptotic cell nuclei red. Scaffolds were cut in half, stained with FDA and PI, as previously described (Zhang et al., 2009a), and viewed under a confocal laser microscope (Olympus, FV1000Fluoview, Japan). Cellular scaffolds were examined in both planar view and crosssectional view after 3 and 9 days of culture.

\section{DNA Assay}

The total DNA from scaffolds cultured with hfMSCs was extracted from each scaffold by incubating the constructs in $0.4 \mathrm{~mL}$ of enzymatic cocktail [consisting of $0.1 \%$ collagenase A
(Roche, Switzerland) with $0.1 \%$ Trypsin mixed in PBS] at $37^{\circ} \mathrm{C}$ for $2 \mathrm{~h}$, with vortex every $30 \mathrm{~min}$ followed by three cycles of freeze and thaw. For haMSCs, after culture all scaffolds were washed gently in PBS, dried by aspirating the PBS, cut in pieces and stored at $-80^{\circ} \mathrm{C}$ for at least $24 \mathrm{~h}$. After thawing, the constructs were digested for $16 \mathrm{~h}$ at $56^{\circ} \mathrm{C}$ with $1 \mathrm{mg} / \mathrm{mL}$ proteinase $\mathrm{K}$ (SigmaAldrich, the Netherlands) in Tris/EDTA buffer ( $\mathrm{pH} 7.6)$. This solution contained $18.5 \mu \mathrm{g} / \mathrm{mL}$ iodoacetamine (Sigma-Aldrich, the Netherlands) and $1 \mu \mathrm{g} / \mathrm{mL}$ Pepstatin A (Sigma-Aldrich, the Netherlands). Quantification of total DNA was done using the CyQuant ${ }^{\circledR}$ DNA assay (Molecular Probes, Fisher Scientific, the Netherlands) and a spectrophotometer (excitation $480 \mathrm{~nm}$, emission $520 \mathrm{~nm}$ ) (Victor 3, Perkin Elmer, the Netherlands).

\section{Hydroxyproline Assay}

Hydroxyproline colorimetric assay kit (Biovision, USA) was performed according to the manufacturer's protocol to determine the total collagen amount on the same samples as used for DNA quantification. In brief, from the digested sample, $30 \mu \mathrm{L}$ was transferred to a Teflon ${ }^{\circledR}$ capped glass bottle. Another $30 \mu \mathrm{L}$ of concentrated hydrochloric acid $(\mathrm{HCl}, 12 \mathrm{M}$, Sigma-Aldrich, the Netherlands) was added and samples were hydrolyzed at $120^{\circ} \mathrm{C}$ 
for $3 \mathrm{~h}$. The complete supernatant was transferred to a 96-well plate and left to evaporate at $60^{\circ} \mathrm{C}$. Subsequently, $100 \mu \mathrm{L}$ of chloramine T/Oxidation buffer mix (Biovision, USA) was added to each well and incubated at room temperature for $5 \mathrm{~min}$. Finally, $100 \mu \mathrm{L}$ of DMAB Reagent (Biovision, USA) was added to each well including the hydroxyproline standard and incubated for 90 min at $60^{\circ} \mathrm{C}$. A micro plate reader (Multiskan GO, Thermo Fisher, the Netherlands) was used to determine the absorbance at $560 \mathrm{~nm}$.

\section{Gene Expression Analysis of hfMSCs and haMSCs}

For gene expression analysis of hfMSCs, samples were seeded ( $n=4$ for static cultures; $n=5$ for the biaxial bioreactor system) at different time points. After culture, medium was aspirated from the scaffolds, the samples were transferred to $2 \mathrm{~mL}$ Eppendorf tubes and stored at $-80^{\circ} \mathrm{C}$. Prior to RNA isolation from the samples by using a Bioke RNA II nucleospin RNA isolation kit (Macherey-Nagel, Germany), first $500 \mu \mathrm{L}$ of TRIzol ${ }^{\circledR}$ (Invitrogen, the Netherlands) was added. The scaffolds were disrupted by crushing with RNA isolation pestles (Kimble Kontes, Fisher Scientific, the Netherlands). Samples for basal gene expression analysis, referred to as T25 day 0, were retrieved from twodimensional (2D) culture in T25 tissue culture flasks (NUNC, Fisher Scientific, the Netherlands) by adding $500 \mu \mathrm{L}$ of TRIzol ${ }^{\circledR}$ (Invitrogen, the Netherlands) upon reaching 70\% confluence. Subsequently, the cell/TRIzol ${ }^{\circledR}$ suspension was transferred to an Eppendorf tube and $200 \mu \mathrm{L}$ of $\mathrm{CHCl}_{3}$ was added to each sample and mixed by vigorously shaking the tubes. The TRIzol ${ }^{\circledR} / \mathrm{CHCl}_{3}$ mixture was centrifuged at $12,000 \times \mathrm{g}$ for $15 \mathrm{~min}$ at $4^{\circ} \mathrm{C}$. The aqueous phase was transferred to a new Eppendorf tube and mixed 1:1 with $70 \%$ ethanol. The mixture was transferred to filter columns from the kit and the RNA isolation was continued following the manufacturer's protocol. RNA concentrations and purity were determined by using an ND1000 spectrophotometer (Nanodrop Technologies, USA). The cDNA was synthesized from 630 ng of RNA, using iScript ${ }^{\mathrm{TM}}$ (BIO-RAD, Bio-rad Laboratories, the Netherlands) according to the manufacturer's protocol. Quantitative polymerase chain reaction (qPCR) was performed on cDNA samples by using the iQ SYBR ${ }^{\circledR}$ Green Supermix (BioRad, the Netherlands) on the primers as listed in Table 1. PCR reactions were carried out on the MyiQ2 Two-Color Real-Time PCR Detection System (Bio-Rad, the Netherlands) under the following conditions: cDNA was denatured for $10 \mathrm{~min}$ at $95^{\circ} \mathrm{C}$, followed by 40 cycles, consisting of $15 \mathrm{~s}$ at $95^{\circ} \mathrm{C}, 30 \mathrm{~s}$ at $60^{\circ} \mathrm{C}$, and $30 \mathrm{~s}$ at $72^{\circ} \mathrm{C}$. For each reaction, a melting curve was generated to test primer dimer formation and non-specific priming. The cycle threshold $(\mathrm{Ct})$ values were determined with the Bio-RadiQ5 optical system software, in which a threshold value was set for the fluorescent signal at the lower log-linear part above the baseline. $\mathrm{Ct}$ values were normalized to the B2M housekeeping gene and $\Delta \mathrm{Ct}$ ((average of $\left.\left.\mathrm{Ct}_{\text {control }}\right)-\mathrm{Ct}_{\text {value }}\right)$. Results are expressed as relative mRNA expression normalized to the gene expression levels of hfMSCs from T25 day 0 and calculated as $2^{-\Delta \mathrm{Ct}}$.

For gene expression analysis of haMSCs, samples were seeded statically for 3 days followed by another 6 days of static culture or 6 days of dynamic culture in the biaxial bioreactor system or in the perfusion-flow bioreactor. After culture, medium was aspirated from the scaffolds, the samples were transferred to $2 \mathrm{~mL}$ Eppendorf tubes and stored at $-80^{\circ} \mathrm{C}$. Samples for basal gene expression analysis (referred to as day 0 static culture) were retrieved from 2D culture in T25 tissue culture asks (NUNC, Fisher Scientific, the Netherlands) by adding $500 \mu \mathrm{L}$ of TRIzol ${ }^{\circledR}$ (Invitrogen, the Netherlands) upon reaching $70 \%$ confluence. RNA isolation, cDNA synthesis, and RT-PCR were carried out as described for hfMSCs. Results are expressed as relative mRNA expression normalized to the gene expression levels of haMSCs from T25 day 0 and calculated as $2^{-\Delta \mathrm{Ct}}$.

\section{Scanning Electron Microscopy Analysis}

Cell morphology, attachment, and distribution were characterized by scanning electron microscopy (SEM) analysis with a Philips XL 30 ESEM-FEG (FEI, the Netherlands). Samples were fixed for $30 \mathrm{~min}$ in $10 \%$ formalin. Subsequently, the samples were dehydrated in sequential ethanol series and critical point dried from liquid carbon dioxide using a Balzers CPD 030 Critical Point Dryer (Leica, Germany). The constructs were gold sputter coated (Cressington, UK) prior to SEM analysis. SEM images were obtained under high vacuum with an acceleration voltage of $30 \mathrm{kV}$ and a working distance of $10 \mathrm{~mm}$.

\section{Methylene Blue Staining}

Cell morphology, attachment, and distribution of haMSCs were qualitatively assessed by methylene blue staining. Samples were fixed for $30 \mathrm{~min}$ in 10\% formalin, washed with PBS twice, and stained with methylene blue (Sigma, the Netherlands) for $30 \mathrm{~s}$ immediately followed by extensive washing with DI-water until the water remained colorless. The samples were imaged using a stereomicroscope (Nikon SMZ800 with Q-imaging Retiga 1300 camera, Nikon Instruments Europe, the Netherlands).

\section{Histological Analysis}

Samples were fixed after live/dead imaging or directly after culture for $30 \mathrm{~min}$ in $10 \%$ formalin and stored in $\mathrm{PBS}$ at $5^{\circ} \mathrm{C}$ until further processing. Samples were dehydrated using a sequential ethanol series $(60,70,80,90,96$, and $100 \%$ ethanol, $30 \mathrm{~min}$ for each step), and subsequently embedded in glycol methacrylate (GMA). The obtained blocks were sectioned at $5 \mu \mathrm{m}$ intervals, and stained with hematoxylin and eosin (H\&E, Sigma, the Netherlands) for visualization of the nuclei and cytoplasm, and Masson Trichrome (Merck, Germany) to stain for collagen-like ECM formation.

\section{Statistical Analyses}

Results are presented as mean $\pm \mathrm{SD}$, and compared using either one-way ANOVA (multiple conditions) with a Bonferroni posttest or Student's $t$-test (two conditions). Statistical significance was set to $p$-value $<0.05\left(^{*}\right)$. 
TABLE 1 | Primer sequences.

\begin{tabular}{|c|c|c|}
\hline Gene & Forward primer & Reverse primer \\
\hline $\mathrm{B} 2 \mathrm{M}$ & GACTTGTCTICAGCAAGGA & ACAAAGTCACATGGTTCACA \\
\hline ALCAM & ACGATGAGGCAGACGAGATAAGT & CAGCAAGGAGGAGACCAACAA \\
\hline CD-63 & GCCCTTGGAATTGCTITGTCG & CATCACCTCGTAGCCACTTCT \\
\hline f-Actin & GGCATCCTCACCCTGAAGTA & GGTGTGGTGCCAGATाTC \\
\hline Runx2 & GGAGTGGACGAGGCAAGAGTाT & AGCTTCTGTCTGTGCCTTCTGG \\
\hline ALP & ACAAGCACTCCCACTTCATC & TTCAGCTCGTACTGCATGTC \\
\hline ACAN & AGGCAGCGTGATCCTTACC & GGCCTCTCCAGTCTCATTCTC \\
\hline Sox9 & TGGGCAAGCTCTGGAGACTTC & ATCCGGGTGGTCCTTCTTGTG \\
\hline Col-1 & GTCACCCACCGACCAAGAAACC & AAGTCCAGGCTGTCCAGGGATG \\
\hline Col-2 & CGTCCAGATGACCTTCCTACG & TGAGCAGGGCCTTCTTGAG \\
\hline
\end{tabular}

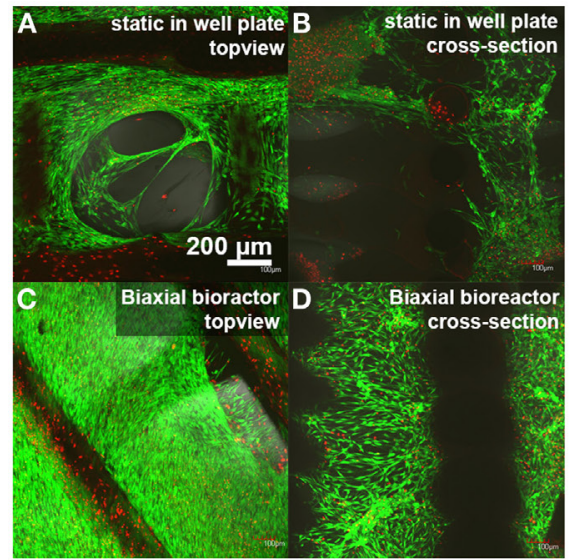

\section{$E$}

\section{DNA quantification}

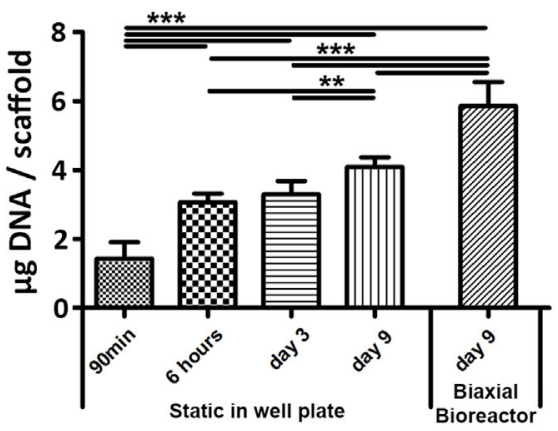

$\mathbf{F}$ Total Collagen per cell

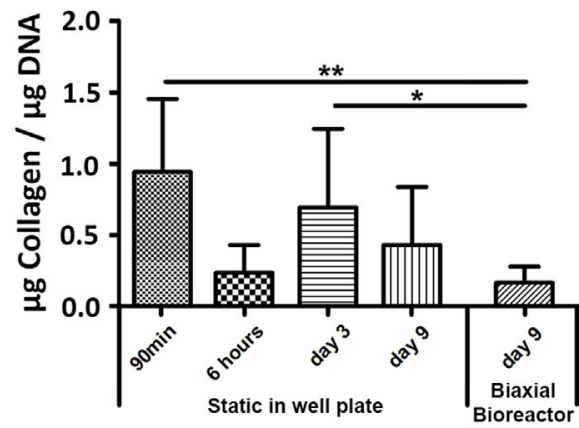

FIGURE 2 | Live/dead staining showed a high cell viability of fetal hMSCs after 9 days of static culture in a well plate (A,B) and after 3 days of culture in static condition in a plate followed by $\mathbf{6}$ days of culture in a biaxial bioreactor (C,D). Higher numbers of cells were found in the scaffolds after culture in the biaxial bioreactor compared to the scaffolds from static culture. This was confirmed by DNA quantification (E) where a significant difference in cell number was found between static culture in a plate and culture in the biaxial bioreactor. DNA quantification also shows a significance increase in cell number in time ( 90 min, 3 , 9 days) when the cells are cultured statically in a well plate. (F) Collagen production per cell did not increase in time and significantly decreased upon culture in the biaxial bioreactor compared to 1 day of static culture subsequent to 90 min of seeding in a concentrated suspension and to 3 days of static culture [90 min and $6 \mathrm{~h}$ $(n=5)$, day $3(n=10)$, day 9 static $(n=12)$, day 9 biaxial bioreactor $\left.(n=14),{ }^{\star} p<0.05,{ }^{\star \star} p<0.01,{ }^{\star \star *} p<0.001\right]$.

\section{RESULTS}

\section{Viability, Distribution, and Gene Expression Profile of hfMSCs}

Scaffolds seeded with hfMSCs showed comparable viability after 9 days of culture in both well plate (static) and in the biaxial bioreactor (Figures 2A,C, respectively). A high viability was also found $6 \mathrm{~h}$ after seeding (Figures S1 A,B in Supplementary Material) and after 3 days of static culture (Figures S1C,D in Supplementary Material). In the cross-sectional view of the scaffolds, it could be observed that the number of hfMSCs and their distribution seemed to be enhanced when the constructs were cultured in the biaxial bioreactor (Figure 2D) compared to the scaffolds with hfMSCs cultured statically in a well plate (Figure 2B). Also, the morphology of the cells in the pores of the scaffolds appeared more spread after culture in the biaxial bioreactor (Figures S1E-H in Supplementary Material). The difference in cell number was confirmed by DNA quantification (Figure 2E). Both the scaffolds in static culture and in the biaxial bioreactor showed an increase in cell number over time; yet, the increase in the biaxial bioreactor was significantly higher than in static culture.

Furthermore, allowing the cells to adhere to the scaffold initially for $6 \mathrm{~h}$ before adding medium resulted in a significant higher cell seeding efficiency than when the medium was added already after $1.5 \mathrm{~h}$ of incubation. A hydroxyproline assay was performed to determine the total amount of intra and extracellular collagen, which is a measure for cells activity and ECM formation (Figure 2F). A small increase in total collagen production per cell was observed between $6 \mathrm{~h}$ and 3 days of static culture, whereas the DNA content remained similar. At later timepoints, the DNA content increased, whereas the total collagen content per scaffold remained constant for these conditions, resulting in a decrease of collagen production per cell. This suggests that hfMSCs were mainly proliferating.

Gene expression levels of ALCAM (CD166, activated leukocyte cell adhesion molecule) and CD63, both indicators for stemness (Jeannet et al., 2013) (Figures 3A,B respectively), fluctuated over time in static culture. ALCAM and CD63 were 

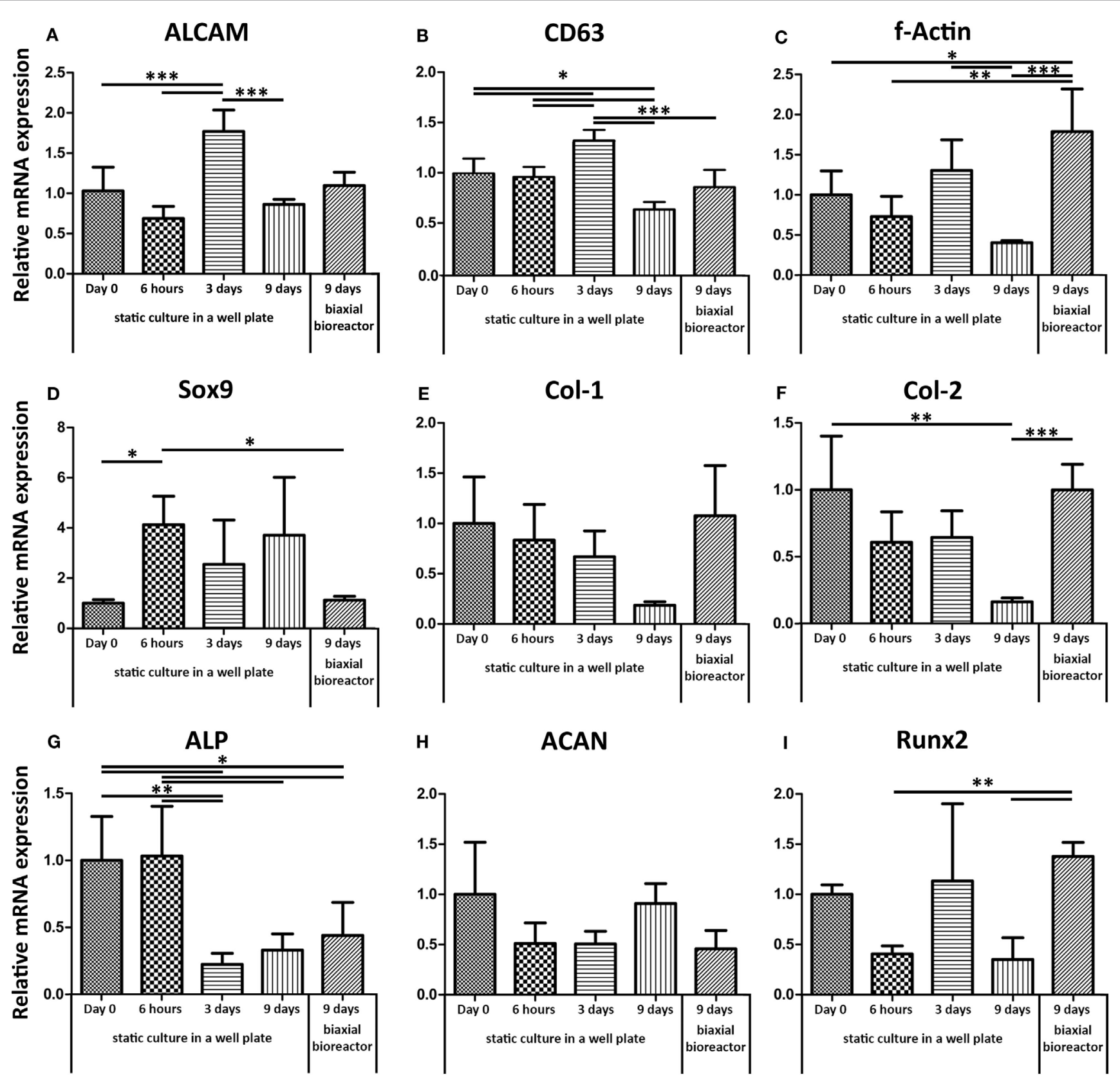

FIGURE 3 | Relative mRNA expression levels were assessed by qPCR. The basal mRNA expression levels were determined for hfMSCs from monolayer culture on tissue culture-treated polystyrene (Day 0). (A,B) ALCAM and CD63, both genes associated with the maintenance of stemness, did not show significant differences between the basal gene expression levels and the expression levels after 9 days of static or biaxial bioreactor culture. (C) F-Actin showed a slight down-regulation after 9 days in static culture and a significant up-regulation after 3 days static followed by 6 days biaxial bioreactor culture. This same trend was found for Runx2 (I). (G) ALP was down-regulated for both static and biaxial bioreactor culture. (H,D) ACAN and Sox9 were down-regulated in convection culture. (E,F) Col-1 and col-2, markers for ECM production, were down-regulated in time in static culture, but retained basal expression levels when the scaffolds were placed in biaxial bioreactor culture $\left[n=4\right.$ except for day 9 dynamic $\left.(n=5),{ }^{*} p<0.05,{ }^{\star \star} p<0.01,{ }^{\star \star \star} p<0.001\right]$.

similarly expressed after 9 days in both static cultures in a well plate and after 9 days of culture in the biaxial bioreactor compared to their basal level measured in cells trypsinized from monolayer culture at a confluence of approximately $70 \%$ (day 0 static). F-actin mRNA expression showed a significant twofold up-regulation in dynamic culture and a twofold down-regulation in static culture after 9 days. A similar but less robust trend was found for Runt-related transcription factor 2 (Runx2), associated with early osteogenic differentiation. Alkaline phosphatase (ALP) expression, involved in osteogenesis, was down-regulated over time both for static and bioreactor culture. 
Aggrecan (ACAN), a marker for chondrogenesis, did not show any significant differences between any of the conditions. Yet, Sox9, an early marker for chondrogenesis, was up-regulated in static culture in a well plate, whereas the biaxial bioreactor system restored the mRNA expression levels similar to the basal levels (day 0 static culture). Collagen type-1 (col-1) and collagen type-2 (col-2) markers for ECM proteins, abundantly present in bone and cartilage, respectively, were both down-regulated over time in static culture, whereas their expression levels were restored upon culture in the biaxial bioreactor system.

Scanning electron microscopy analysis was performed on cross-sections of the scaffolds after 9 days of culture to assess cell distribution, morphology, and tissue formation (Figure 4). Statically cultured scaffolds (Figures 4A,C,E) showed lower cell numbers compared to scaffolds cultured in the biaxial bioreactor (Figures $\mathbf{4 B}, \mathbf{D}, \mathbf{F}$ ). The cellular distribution appeared more homogeneous and the cells invaded the longitudinal pores of the scaffold more profoundly after culture in the biaxial bioreactor system compared to culture in static conditions. There were no large differences observed in ECM formation and cell morphology between static culture and culture in the biaxial bioreactor system. In both conditions, the cells were spread while partly attached to the scaffold material or the secreted ECM. The formed tissue appeared relatively open inside the pores of the scaffolds, whereas the outer layer of tissue found at the bottom or top of the scaffold appeared as a more dense and closed layer.

From the SEM analysis after $6 \mathrm{~h}$ (Figures S2A-C in Supplementary Material) and 3 days of static culture (Figures S2D-F in Supplementary Material), it could be seen that the cell morphology changed over time from a rounded shape to a more spread morphology. Similar cell-shape changes were observed in $2 \mathrm{D}$ culture where hfMSCs showed a more spread morphology upon attachment to the substrate material. This change in cellular morphology could also be observed in histological analysis by H\&E staining (Figure S3 in Supplementary Material). Further analysis with Masson Trichrome staining showed collagen-like materials stained green, which did not show any differences between 9 days of static culture in a well plate and 9 days of culture in the biaxial bioreactor (Figure S4 in Supplementary Material).

\section{The Cell Adherence, Distribution, and Gene Expression Profile of haMSCs}

Comparing the methylene blue staining of haMSCs after 3 days of static culture followed by 6 days of culture in a biaxial bioreactor (Figure S5B in Supplementary Material) to the staining after 9 days of static culture in a well plate (Figure S5A in Supplementary Material), no improvement on cell number and cellular distribution was found upon bioreactor culture. In static culture, haMSCs adhered to the fibers and partly filled the pores of the scaffold probably upon proliferation and ECM production (Figure S5A in Supplementary Material). In the biaxial bioreactor culture, the cells did not fill the pores of the scaffold to the same extend as the cells in static culture. From the cross-sectional view, it could be observed that the distribution of the cells throughout the scaffold was still limited in both conditions. Donor 2 showed limited cell adherence after 3 days of static culture in a well plate followed by 6 days of culture in the perfusion bioreactor (Figure S5C in Supplementary Material).

The DNA content was quantified for two donors in triplicate (Figure S6 in Supplementary Material). The results showed on average a relatively low DNA content (about a threefold less compared to hfMSCs) in both bioreactors. For donor 1, a slight increase in DNA content was found upon bioreactor culture compared to static culture. Donor 2, however, showed a significant difference between static and perfusion culture, and between the biaxial bioreactor and the perfusion bioreactor culture. For this same donor, higher cell numbers were also observed in static culture compared to culture in the biaxial bioreactor or in the perfusion bioreactor when the constructs were cultured statically in a well plate for 31 days prior to a 14 days culture in the two bioreactor systems (Figure S7 in Supplementary Material). These findings were confirmed by DNA assay in which a significant drop in DNA content was observed after the scaffolds were cultured in the biaxial bioreactor or perfusion bioreactor culture compared to the DNA content after 31 and 45 days of static culture (Figure S8 in Supplementary Material).

The gene expression profile of haMSCs was assessed for the same genes as hfMSCs (Figure 5). The gene expression levels were determined after 9 days of static culture and compared to gene expression levels of haMSCs after 3 days of static culture followed by 6 days of dynamic culture in the biaxial bioreactor or in the perfusion bioreactor. A significant twofold down-regulation of ALCAM was found for haMSCs cultured in a perfusion bioreactor compared to static culture and culture in the biaxial bioreactor. F-Actin, col-1, and col-2 showed a significant downregulation in both dynamic culture systems compared to static culture. Sox- 9 was significantly down-regulated in the biaxial bioreactor and ACAN was up-regulated a 10 -fold in perfusion culture compared to static culture. However, this change was not statistically significant.

\section{DISCUSSION}

Mesenchymal stromal cells derived from bone marrow have been used as a cellular source in several tissue engineering applications due to their availability, ease of isolation from autologous source and therewith reduced immunological-related risks upon re-implantation. Moreover, MSCs have shown a certain degree of plasticity by the ability to differentiate and transdifferentiate after differentiation into several well-defined cell lineages both in vitro and in vivo (Phinney et al., 1999; Grove et al., 2004; Song and Tuan, 2004; Phinney, 2007; Russell et al., 2010; Ullah et al., 2013).

The multipotency of MSCs is often assessed by soluble factorinduced differentiation in which the results of histological or biochemical assays are used to characterize cell fate. However, instead of focusing on changes in MSCs phenotype by quantifying the expression of differentiation-related genes, it could be also of interest to assess to what extent the cellular phenotype of MSCs can be maintained by investigating genes related to multipotency. 


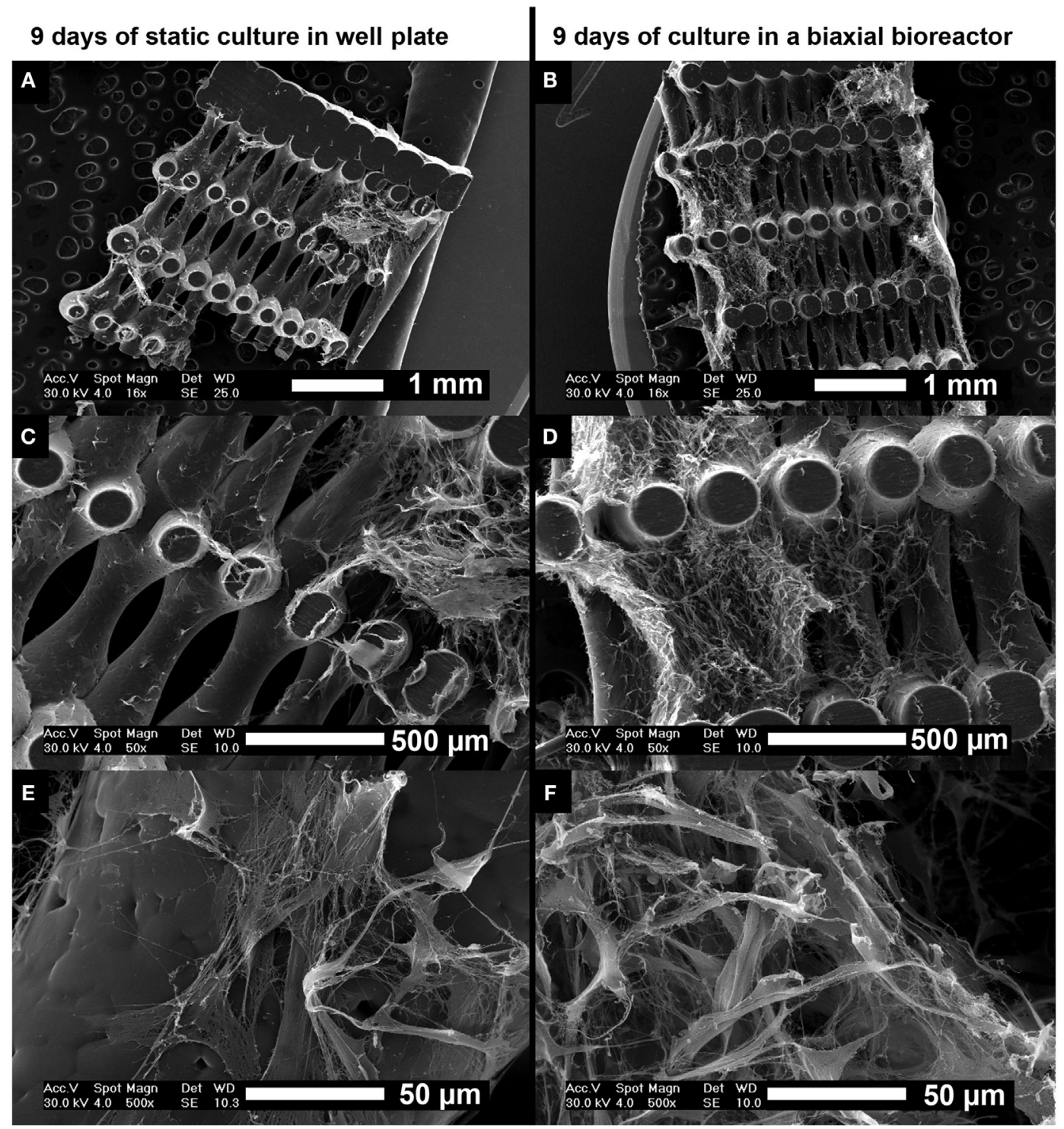

FIGURE 4 | Scanning electron microscopy images of the distribution of hfMSCs throughout the scaffolds after 9 days of static culture in a well plate $(A, C, E)$ and after 3 days of static followed by 6 days of dynamic culture in a biaxial rotating bioreactor (B,D,F). A slightly more homogeneous distribution of cells and ECM was found after culture in the biaxial bioreactor compared to static culture in a well plate. Scale bars represent (A,B) $1 \mathrm{~mm}$, (C,D) $500 \mu \mathrm{m}$, and (E,F) $50 \mu \mathrm{m}$.

In the past decades, researchers focused on defining stemness and identifying stemness markers to be able to more directly assess the potency of patient-derived MSC populations (Menicanin et al., 2009).

A known drawback in the use of haMSC is their slow proliferation time and generally limited proliferation capacity. More recently, hfMSCs have been characterized showing a higher proliferation and osteogenic differentiation capacity and reduced immunogenicity when compared to mesenchymal stem cell populations derived from the umbilical cord, adult adipose tissue, or adult bone marrow in $3 \mathrm{D}$ culture systems both in vitro and in vivo (Zhang et al., 2009a). Here, we have assessed hfMSCs and haMSCs behavior in 3D scaffolds with respect to cell attachment, proliferation, and genetic profile.

Static and bioreactor culture conditions both resulted in similar cell viability on the PEOT/PBT scaffolds (Figures 2A-D). However, the number of hfMSCs in the biaxial bioreactor culture was higher (Figure 2E) and the distribution of the cells throughout the scaffolds seemed to be improved with respect to the scaffolds in static culture in a well plate (Figures 2A-D and Figure 4). With respect to the gene expression levels, it could be concluded that 6 days of biaxial bioreactor culture subsequent to 3 days of static 


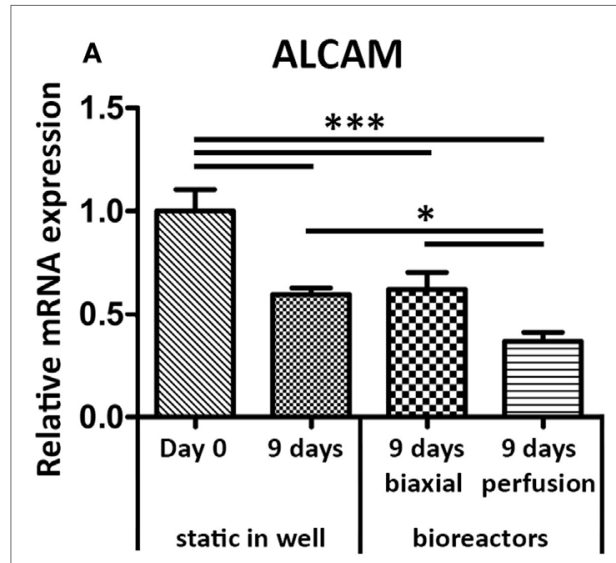

D
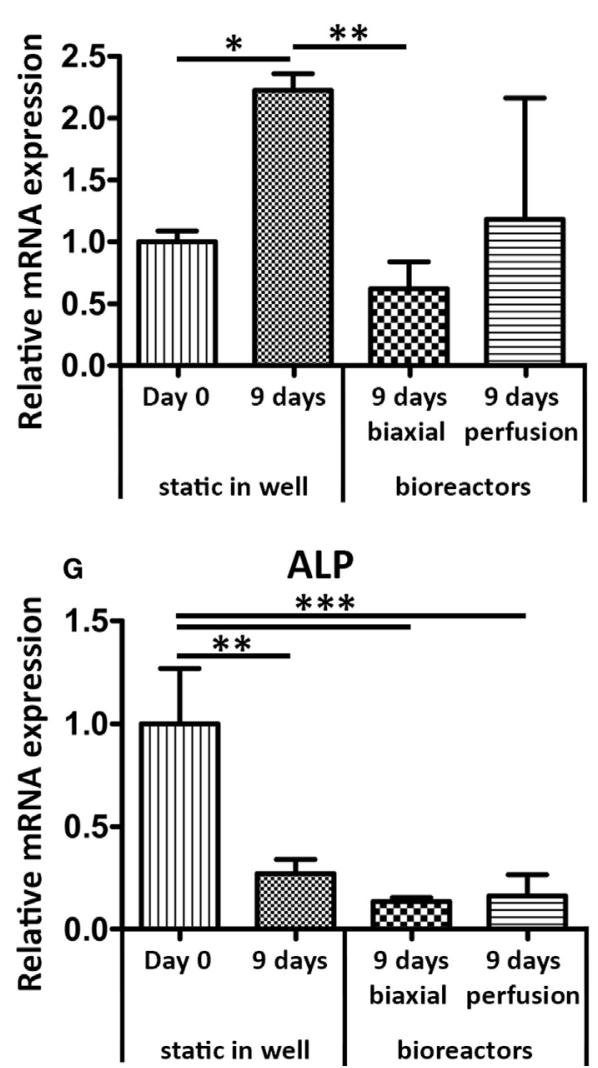

B

CD63

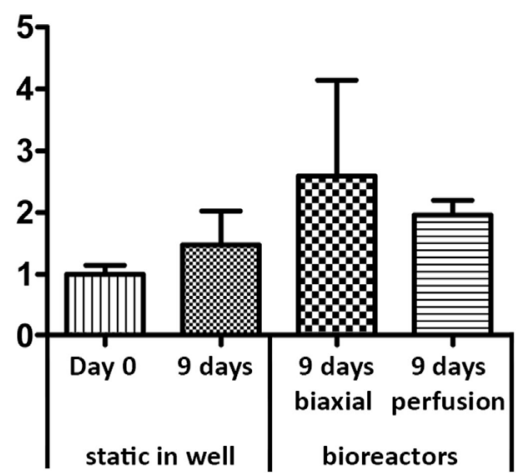

E

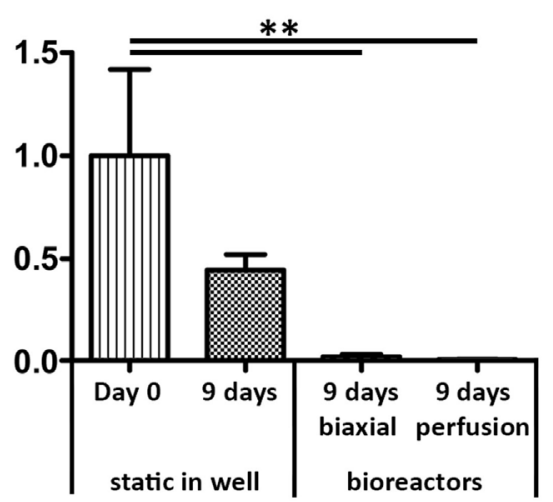

H

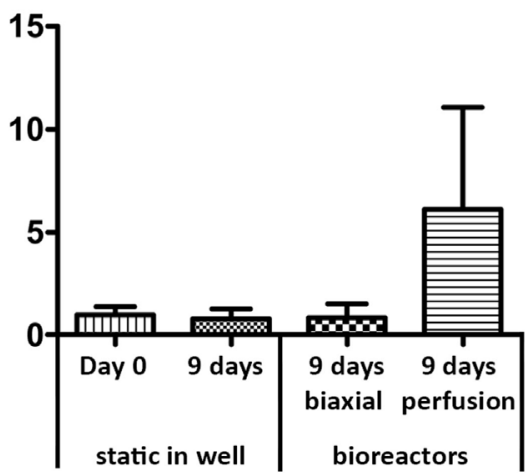

C f-Actin

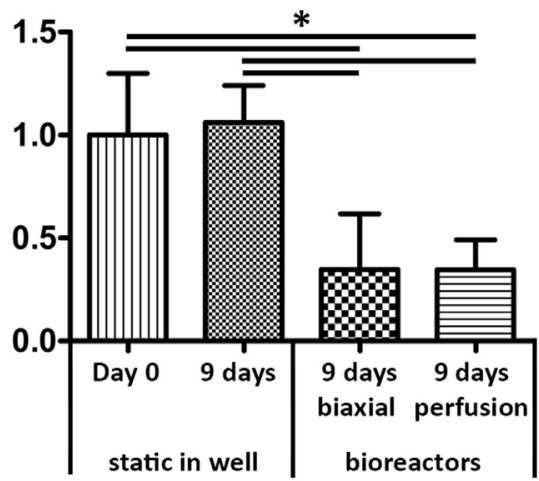

$\mathbf{F}$

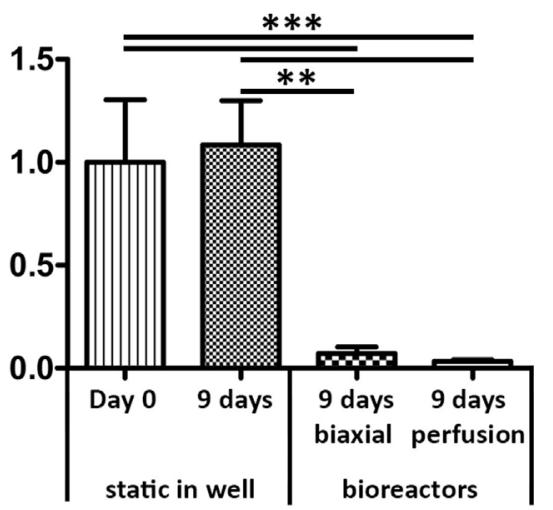

I Runx2

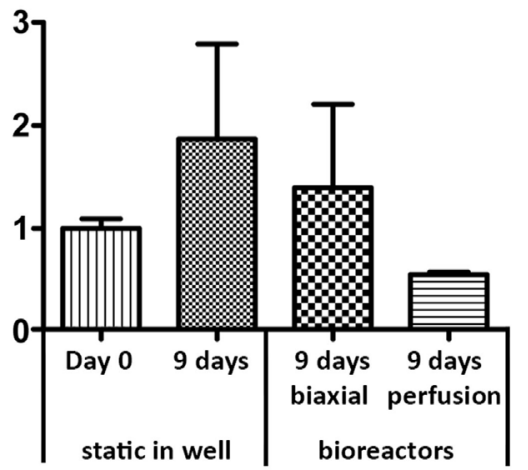

FIGURE 5 | Relative mRNA expression levels of haMSCs in static, biaxial bioreactor, and perfusion bioreactor culture were assessed by qPCR. (A) ALCAM showed a twofold significant down-regulation after 9 days of perfusion culture compared to static and biaxial bioreactor cultures. (B) CD63 showed no significant differences between the different culture systems. (C) F-Actin showed a down-regulation after 9 days in both dynamic culture systems compared to static culture. (D) Sox9 was significantly up-regulated in static culture in a well plate, whereas the bioreactor systems restored the mRNA expression levels similar to the basal levels (day 0 static culture). (E,F) Col-1 and Col-2, markers for extra-cellular matrix production, were down-regulated in both dynamic culture systems.

(G) ALP showed a significant down-regulation in all conditions after 9 days of culture compared to day 0 in static culture. (H) ACAN showed a 10-fold up-regulation after perfusion culture compared to static and biaxial bioreactor culture; however, this change was not statistically significant. (I) For Runx2, no significant differences between the different culture conditions were found $\left(n=3,{ }^{*} p<0.05,{ }^{\star *} p<0.01,{ }^{\star \star *} p<0.001\right)$.

culture restored the basal gene expression levels, found at day 0 in static monolayer culture, for all genes except ALP and f-actin. Similar results were found by a study of Katayama et al. (2013), in which no change in gene expression levels of stem cell markers, such as ALCAM, was found in adult hMSCs cultured on collagen sheets under perfusion flow.
Considering the genes involved in ECM production, such as f-actin, col-1, and col-2, static culture seemed to provide insufficient cues to the cells to activate ECM formation-related pathways. Col-1 and col-2 expressions were maintained in the biaxial bioreactor culture and down-regulated in static culture. This indicated that the hfMSCs in the biaxial bioreactor probably 
experienced shear forces, due to a sort of convection flow, resulting in activation of the f-actin pathway among others, which could subsequently lead to an increase in tissue formation (Sansores-Garcia et al., 2011). Furthermore, shear forces have been known to induce osteogenic differentiation, which could explain the initial significant decrease of ALP expression in static culture and the subsequent small increase in ALP in the biaxial bioreactor (Figure 3) (Yeatts et al., 2012). On the other hand, a recent study of Kock et al. (2014) has shown a negative influence of perfusion flow on cartilage-like ECM production of chondrogenic pre-differentiated hMSCs, although these changes were not evident from gene expression analysis (Kock et al., 2014).

Scanning electron microscopy analysis (Figures 4E,F) showed an increase in tissue formation and tissue density was observed for dynamically cultured samples compared to statically cultured scaffolds. Although 6 days of culture in the biaxial bioreactor may have altered the gene expression levels compared to static culture, no difference was found on total collagen production by biochemical and histological analysis (Figure 2F and Figures S4E-H in Supplementary Material, respectively). However, the number of cells in the interior of the scaffold in the biaxial bioreactor was higher than in static culture conditions, indicating that bioreactor culture did improve cellular distribution.

Although hfMSCs have shown some beneficial properties over haMSCs in previous studies, the application of haMSCs remained of interest due to their more immediate clinical relevance. Fetal MSCs cannot be used from autologous source and their use involves more ethical issues. Therefore, the use of haMSCs on these scaffolds in the biaxial bioreactor was evaluated as well. A perfusion-flow bioreactor was introduced in parallel to be able to compare the results obtained in the biaxial bioreactor culture to both static and perfusion culture conditions. The cell number of haMSCs per scaffold assessed by DNA assay after 9 days of static culture was found to be significantly lower for both haMSC donors (Figure S6 in Supplementary Material) compared to hfMSCs (Figure 2E). Cell seeding efficiency of haMSCs has already shown to be limited and donor dependent in one of our previous studies, in which several seeding parameters were optimized to decrease cell loss after seeding (Leferink et al., 2013).

For the two haMSCs donors, no difference in the number of cells was found upon culture in the biaxial bioreactor compared to static culture conditions. Similar results were found in a study of Stiehler et al. (2009), in which hMSCs seeded on PLGA-based scaffolds did not show any difference in cell number after 7 days of convection culture compared to static culture. In other studies, perfusion culture was applied on porous $3 \mathrm{D}$ scaffolds and showed to improve cell proliferation and scaffold colonization (Alvarez-Barreto et al., 2007; Bjerre et al., 2008; Grayson et al., 2008, 2011; Schumacher et al., 2010). In our study, however, perfusion culture showed to significantly decrease the number of haMSCs from donor 2 compared to static culture or culture in the biaxial bioreactor. This could be due to the highly interconnected and organized pore network of additive manufactured scaffolds compared to more conventional sponges and non-woven scaffolds with random fiber organization used in previous studies. A similar negative effect was reported in a study by Bjerre et al.
(2011) in which perfusion culture unfavorably changed the morphology and vitality of haMSCs (Bjerre et al., 2011).

Differences in initial cell attachment between the two donors could be an effect of differences in heterogeneity of cell populations due to donor variation (DiGirolamo et al., 1999; Phinney et al., 1999; Siddappa et al., 2007; Leferink et al., 2013; Siegel et al., 2013). Changes in cell response to the introduction of perfusion flow could also be related to several other factors such as the amount of ECM produced at the moment of transfer from static culture to the perfusion-flow system and the distribution of the cells and ECM throughout the scaffold. Upon closure of the longitudinal pores of the scaffold due to the presence of the formed ECM in static culture, the pressure, or the perfusion flow is expected to be increased, which could have led to tissue detachment. We hypothesized that prolonging the static culture period prior to applying bioreactor culture could result in more ECM with stronger binding and entanglement to the scaffold material (Griffon et al., 2011). Therefore, the scaffolds were cultured statically for 31 days followed by 14 days of culture in the biaxial bioreactor or in the perfusion bioreactor. From cross-sectional views on methylene blue stained scaffolds (Figure S7 in Supplementary Material), it could be observed that the cells and tissues indeed seemed to be detached from the scaffold upon dynamic culture, whereas in static conditions, a homogeneous distribution of cells and tissue throughout the scaffold was found. These results were confirmed by DNA quantification, which showed a significant loss of cells upon transferring the constructs from static to bioreactor culture (Figure S8 in Supplementary Material). In both the biaxial bioreactor and the perfusion bioreactor, loosened cell sheets were found in the longitudinal pores of the scaffolds. A difference between the two bioreactor systems was found with respect to the adherence sites of the cells. In perfusion culture conditions, cells were found on the outer layer of scaffold material, whereas in the biaxial bioreactor, lesser cells were found to reside on the outer layer of the scaffold.

The gene expression levels of f-actin, col-1, and col-2 previously showed to be significantly up-regulated in hfMSCs, whereas a significant down-regulation was found in haMSCs when comparing the basal gene expression levels and the levels after 9 days of static culture to the levels after 3 days of static culture followed by 6 days of culture in the biaxial bioreactor. For Sox- 9 , a similar response was found for hfMSCs compared to haMSCs. ALCAM, CD63, and ACAN did not show any significant differences in hfMSCs and haMSCs cultured statically or dynamically in the biaxial bioreactor. Larger differences in gene expression levels were found between perfusion culture and static culture than between culture in the biaxial bioreactor and static culture. ALCAM, f-Actin, col-1, and col-2 were significantly downregulated in perfusion culture compared to static culture after 9 days. This could have been related to the lower cell number as a consequence of relatively high shear forces involved in a perfusion culture system.

Overall, the results presented in this study suggested that a more homogeneous cell distribution could be obtained for fetal MSCs compared to adult ones in all conditions, and that the benefit of applying bioreactor culture over static culture was not 
obvious for adult MSCs. Although the experiments with haMSCs were not as successful as with hfMSCs with respect to cell number and distribution, we believe that there is still the potential for a bioreactor system in a later stage of tissue culture with haMSCs. When static cultures lead to complete filling of the scaffold with closure of the pores, cells in the scaffold interior might undergo necrosis by mass transfer limitations. At that stage, a dynamic system, such as the biaxial rotating vessel presented in this study, might become favorable over static culture. Furthermore, in our study, the complex influence of rotational speed and medium perfusion speed on the fluid dynamics was not modeled. Screening the influence of these parameters on MSC fate in additive manufactured scaffolds might result in optimal culture conditions in which a homogeneous distribution throughout the scaffold can be achieved without compromising cells viability or altering MSCs phenotype.

\section{CONCLUSION}

The biaxial rotating vessel bioreactor used in this study has shown to improve hfMSCs distribution and proliferation in $3 \mathrm{D}$ additive manufactured PEOT/PBT scaffolds. The hfMSCs in the biaxial bioreactor produced ECM while retaining a comparable gene expression profile as the basal levels of hfMSCs seeded statically in 2D. Static culture on 3D scaffolds with hfMSCs showed downregulation of f-actin, col-1, col-2, ALP, and runx2 gene expression levels and also resulted in less ECM production and lower cell numbers than in the biaxial bioreactor, thus suggesting a more quiescent state of hfMSCs. As a third well-known dynamic culture system, a perfusion bioreactor was introduced for the experiments

\section{REFERENCES}

Abarrategi, A., Fernandez-Valle, M. E., Desmet, T., Castejon, D., Civantos, A., Moreno-Vicente, C., et al. (2012). Label-free magnetic resonance imaging to locate live cells in three-dimensional porous scaffolds. J. R. Soc. Interface 9, 2321-2331. doi:10.1098/rsif.2012.0068

Alvarez-Barreto, J. F., Linehan, S. M., Shambaugh, R. L., and Sikavitsas, V. I. (2007). Flow perfusion improves seeding of tissue engineering scaffolds with different architectures. Ann. Biomed. Eng. 35, 429-442. doi:10.1007/s10439-006-9244-z

Beumer, G. J., van Blitterswijk, C. A., and Ponec, M. (1994). Biocompatibility of a biodegradable matrix used as a skin substitute: an in vivo evaluation. J. Biomed. Mater. Res. 28, 545-552. doi:10.1002/jbm.820280504

Bjerre, L., Bunger, C., Baatrup, A., Kassem, M., and Mygind, T. (2011). Flow perfusion culture of human mesenchymal stem cells on coralline hydroxyapatite scaffolds with various pore sizes. J. Biomed. Mater. Res. 97, 251-263. doi:10.1002/jbm.a.33051

Bjerre, L., Bunger, C. E., Kassem, M., and Mygind, T. (2008). Flow perfusion culture of human mesenchymal stem cells on silicate-substituted tricalcium phosphate scaffolds. Biomaterials 29, 2616-2627. doi:10.1016/j. biomaterials.2008.03.003

Bossolasco, P., Corti, S., Strazzer, S., Borsotti, C., Del Bo, R., and Fortunato, F. (2004). Skeletal muscle differentiation potential of human adult bone marrow cells. Exp. Cell Res. 295, 66-78. doi:10.1016/j.yexcr.2003.12.015

Brady, K., Dickinson, S. C., Guillot, P. V., Polak, J., Blom, A. W., Kafienah, W., et al. (2014). Human fetal and adult bone marrow-derived mesenchymal stem cells use different signaling pathways for the initiation of chondrogenesis. Stem Cells Dev. 23, 541-554. doi:10.1089/scd.2013.0301

Chan, J., Waddington, S. N., O'Donoghue, K., Kurata, H., Guillot, P. V., Gotherstrom, C., et al. (2007). Widespread distribution and muscle differentiation of human with a more clinically relevant haMSCs population. No increase in cell number and cellular distribution upon culture in the biaxial or the perfusion bioreactor was observed for haMSCs, even after an extended period of static culture prior to culture in the biaxial bioreactors. In addition, the gene expression profile of haMSCs showed a different response to the culture in the biaxial bioreactor than the profile of hfMSCs. There were no consistent significant differences in cell number between 9 days of static culture and 3 days of static culture followed by 6 days of bioreactor culture in both the biaxial bioreactor and the perfusion-flow bioreactor. Overall, the biaxial rotating vessel bioreactor introduced in this study has shown to maintain hfMSCs viability and distribution throughout the scaffold, without inducing differentiation. Therefore, this system could serve as a tool to study cell activity in distinct 3D scaffolds.

\section{ACKNOWLEDGMENTS}

The authors gratefully acknowledge the funding from the Netherlands Institute for Regenerative Medicine (NIRM) through the grant number FES0908. This project/research has been made possible also with the support of the Dutch Province of Limburg. The authors would like to acknowledge Hui-Lun Soh from Quintech Life Sciences Pte Ltd. Singapore for her help in the experiments regarding hfMSCs.

\section{SUPPLEMENTARY MATERIAL}

The Supplementary Material for this article can be found online at http://journal.frontiersin.org/article/10.3389/fbioe.2015.00169

fetal mesenchymal stem cells after intrauterine transplantation in dystrophic MDX mouse. Stem Cells 25, 875-884. doi:10.1634/stemcells.2006-0694

Claase, M. B., de Bruijn, J. D., Grijpma, D. W., and Feijen, J. (2007). Ectopic bone formation in cell-seeded poly(ethylene oxide)/poly(butylene terephthalate) copolymer scaffolds of varying porosity. J. Mater. Sci. Mater. Med. 18, 1299-1307. doi:10.1007/s10856-006-0077-y

de Bruijn, J. D., van den Brink, I., Mendes, S., Dekker, R., Bovell, Y. P., and van Blitterswijk, C. A. (1999). Bone induction by implants coated with cultured osteogenic bone marrow cells. Adv. Dent. Res. 13, 74-81. doi:10.1177/089593 74990130011801

Deschamps, A. A., Claase, M. B., Sleijster, W. J., de Bruijn, J. D., Grijpma, D. W., and Feijen, J. (2002). Design of segmented poly(ether ester) materials and structures for the tissue engineering of bone. J. Control. Release 78, 175-186. doi:10.1016/ S0168-3659(01)00497-7

DiGirolamo, C. M., Stokes, D., Colter, D., Phinney, D. G., Class, R., and Prockop, D. J. (1999). Propagation and senescence of human marrow stromal cells in culture: a simple colony-forming assay identifies samples with the greatest potential to propagate and differentiate. Br. J. Haematol. 107, 275-281. doi:10.1046/j.1365-2141.1999.01715.x

Grayson, W. L., Bhumiratana, S., Cannizzaro, C., Chao, P. H., Lennon, D. P., Caplan, A. I., et al. (2008). Effects of initial seeding density and fluid perfusion rate on formation of tissue-engineered bone. Tissue Eng. 14, 1809-1820. doi:10.1089/ ten.tea.2007.0255

Grayson, W. L., Marolt, D., Bhumiratana, S., Frohlich, M., Guo, X. E., and VunjakNovakovic, G. (2011). Optimizing the medium perfusion rate in bone tissue engineering bioreactors. Biotechnol. Bioeng. 108, 1159-1170. doi:10.1002/ bit. 23024

Griffon, D. J., Abulencia, J. P., Ragetly, G. R., Fredericks, L. P., and Chaieb, S. (2011). A comparative study of seeding techniques and three-dimensional 
matrices for mesenchymal cell attachment. J. Tissue Eng. Regen. Med. 5, 169-179. doi:10.1002/term.302

Grove, J. E., Bruscia, E., and Krause, D. S. (2004). Plasticity of bone marrow-derived stem cells. Stem Cells 22, 487-500. doi:10.1634/stemcells.22-4-487

Guillot, P. V., De Bari, C., Dell'Accio, F., Kurata, H., Polak, J., and Fisk, N. M. (2008). Comparative osteogenic transcription profiling of various fetal and adult mesenchymal stem cell sources. Differentiation 76, 946-957. doi:10.1111/j.1432-0436.2008.00279.x

Janeczek Portalska, K., Leferink, A., Groen, N., Fernandes, H., Moroni, L., van Blitterswijk, C., et al. (2012). Endothelial differentiation of mesenchymal stromal cells. PLoS ONE 7:e46842. doi:10.1371/journal.pone.0046842

Janssen, F. W., Oostra, J., Oorschot, A., and van Blitterswijk, C. A. (2006). A perfusion bioreactor system capable of producing clinically relevant volumes of tissue-engineered bone: in vivo bone formation showing proof of concept. Biomaterials 27, 315-323. doi:10.1016/j.biomaterials.2005.07.044

Jeannet, R., Cai, Q., Liu, H., Vu, H., and Kuo, Y. H. (2013). Alcam regulates longterm hematopoietic stem cell engraftment and self-renewal. Stem Cells 31, 560-571. doi:10.1002/stem.1309

Jo, C. H., Kim, O. S., Park, E. Y., Kim, B. J., Lee, J. H., Kang, S. B., et al. (2008). Fetal mesenchymal stem cells derived from human umbilical cord sustain primitive characteristics during extensive expansion. Cell Tissue Res. 334, 423-433. doi:10.1007/s00441-008-0696-3

Katayama, A., Arano, T., Sato, T., Ikada, Y., and Yoshinari, M. (2013). Radial-flow bioreactor enables uniform proliferation of human mesenchymal stem cells throughout a three-dimensional scaffold. Tissue Eng. Part C Methods 19, 109-116. doi:10.1089/ten.TEC.2011.0722

Kim, J., McBride, S., Tellis, B., Alvarez-Urena, P., Song, Y. H., Dean, D. D., et al. (2012). Rapid-prototyped PLGA/beta-TCP/hydroxyapatite nanocomposite scaffolds in a rabbit femoral defect model. Biofabrication 4, 025003. doi:10.1088/1758-5082/4/2/025003

Kock, L. M., Malda, J., Dhert, W. J., Ito, K., and Gawlitta, D. (2014). Flow-perfusion interferes with chondrogenic and hypertrophic matrix production by mesenchymal stem cells. J. Biomech. 47, 2122-2129. doi:10.1016/j.jbiomech.2013.11.006

Langer, R., and Vacanti, J. P. (1993). Tissue engineering. Science 260, 920-926. doi:10.1126/science.8493529

Leferink, A. M., Hendrikson, W. J., Rouwkema, J., Karperien, M., van Blitterswijk, C. A., and Moroni, L. (2013). Increased cell seeding efficiency in bioplotted three-dimensional PEOT/PBT scaffolds. J. Tissue Eng. Regen. Med. doi:10.1002/ term. 1842

Mackay, A. M., Beck, S. C., Murphy, J. M., Barry, F. P., Chichester, C. O., and Pittenger, M. F. (1998). Chondrogenic differentiation of cultured human mesenchymal stem cells from marrow. Tissue Eng. 4, 415-428. doi:10.1089/ ten.1998.4.415

Martin, I., Wendt, D., and Heberer, M. (2004). The role of bioreactors in tissue engineering. Trends Biotechnol. 22, 80-86. doi:10.1016/j.tibtech.2003.12.001

Menicanin, D., Bartold, P. M., Zannettino, A. C., and Gronthos, S. (2009). Genomic profiling of mesenchymal stem cells. Stem Cell. Rev. 5, 36-50. doi:10.1007/ s12015-009-9056-2

Moroni, L., de Wijn, J. R., and van Blitterswijk, C. A. (2005). Three-dimensional fiber-deposited PEOT/PBT copolymer scaffolds for tissue engineering: influence of porosity, molecular network mesh size, and swelling in aqueous media on dynamic mechanical properties. J. Biomed. Mater. Res. 75, 957-965. doi:10.1002/jbm.a.30499

Moroni, L., Schotel, R., Hamann, D., de Wijn, J. R., and van Blitterswijk, C. A. (2008). 3D fiber-deposited electrospun integrated scaffolds enhance cartilage tissue formation. Adv. Funct. Mater. 18, 53-60. doi:10.1002/ adfm. 200601158

Muguruma, Y., Reyes, M., Nakamura, Y., Sato, T., Matsuzawa, H., Miyatake, H., et al. (2003). In vivo and in vitro differentiation of myocytes from human bone marrow-derived multipotent progenitor cell. Exp. Hematol. 31, 1323-1330. doi:10.1016/j.exphem.2003.09.003

Papadimitropoulos, A., Riboldi, S. A., Tonnarelli, B., Piccinini, E., Woodruff, M. A., Hutmacher, D. W., et al. (2013). A collagen network phase improves cell seeding of open-pore structure scaffolds under perfusion. J. Tissue Eng. Regen. Med. 7, 183-191. doi:10.1002/term.506

Phinney, D. G. (2007). Biochemical heterogeneity of mesenchymal stem cell populations: clues to their therapeutic efficacy. Cell Cycle 6, 2884-2889. doi:10.4161/ cc.6.23.5095
Phinney, D. G., Kopen, G., Righter, W., Webster, S., Tremain, N., and Prockop, D. J. (1999). Donor variation in the growth properties and osteogenic potential of human marrow stromal cells. J. Cell. Biochem. 75, 424-436. doi:10.1002/ (SICI) 1097-4644(19991201)75:3<424::AID-JCB8>3.3.CO;2-\#

Pittenger, M. F., Mackay, A. M., Beck, S. C., Jaiswal, R. K., Douglas, R., Mosca, J. D., et al. (1999). Multilineage potential of adult human mesenchymal stem cells. Science 284, 143-147. doi:10.1126/science.284.5411.143

Reichert, J. C., Cipitria, A., Epari, D. R., Saifzadeh, S., Krishnakanth, P., Berner, A., et al. (2012). A tissue engineering solution for segmental defect regeneration in load-bearing long bones. Sci. Transl. Med. 4, 141ra93. doi:10.1126/ scitranslmed.3003720

Russell, K. C., Phinney, D. G., Lacey, M. R., Barrilleaux, B. L., Meyertholen, K. E., and O'Connor, K. C. (2010). In vitro high-capacity assay to quantify the clonal heterogeneity in trilineage potential of mesenchymal stem cells reveals a complex hierarchy of lineage commitment. Stem Cells 28, 788-798. doi:10.1002/ stem. 312

Sansores-Garcia, L., Bossuyt, W., Wada, K., Yonemura, S., Tao, C., Sasaki, H., et al. (2011). Modulating F-actin organization induces organ growth by affecting the Hippo pathway. EMBO J. 30, 2325-2335. doi:10.1038/emboj.2011.157

Schantz, J. T., Machens, H. G., Schilling, A. F., and Teoh, S. H. (2012). Regenerative medicine: implications for craniofacial surgery. J. Craniofac. Surg. 23, 530-536. doi:10.1097/SCS.0b013e318241dc3a

Schumacher, M., Uhl, F., Detsch, R., Deisinger, U., and Ziegler, G. (2010). Static and dynamic cultivation of bone marrow stromal cells on biphasic calcium phosphate scaffolds derived from an indirect rapid prototyping technique. J. Mater. Sci. Mater. Med. 21, 3039-3048. doi:10.1007/ s10856-010-4153-y

Siddappa, R., Licht, R., van Blitterswijk, C., and de Boer, J. (2007). Donor variation and loss of multipotency during in vitro expansion of human mesenchymal stem cells for bone tissue engineering. J. Orthop. Res. 25, 1029-1041. doi:10.1002/ jor.20402

Siegel, G., Kluba, T., Hermanutz-Klein, U., Bieback, K., Northoff, H., and Schafer, R. (2013). Phenotype, donor age and gender affect function of human bone marrow-derived mesenchymal stromal cells. BMC Med. 11:146. doi:10.1186/1741-7015-11-146

Singh, H., Teoh, S. H., Low, H. T., and Hutmacher, D. W. (2005). Flow modelling within a scaffold under the influence of uni-axial and bi-axial bioreactor rotation. J. Biotechnol. 119, 181-196. doi:10.1016/j.jbiotec.2005.03.021

Sobral, J. M., Caridade, S. G., Sousa, R. A., Mano, J. F., and Reis, R. L. (2011). Three-dimensional plotted scaffolds with controlled pore size gradients: effect of scaffold geometry on mechanical performance and cell seeding efficiency. Acta Biomater. 7, 1009-1018. doi:10.1016/j.actbio.2010.11.003

Song, L., and Tuan, R. S. (2004). Transdifferentiation potential of human mesenchymal stem cells derived from bone marrow. FASEB J. 18, 980-982.

Stiehler, M., Bunger, C., Baatrup, A., Lind, M., Kassem, M., and Mygind, T. (2009). Effect of dynamic 3-D culture on proliferation, distribution, and osteogenic differentiation of human mesenchymal stem cells. J. Biomed. Mater. Res. 89, 96-107. doi:10.1002/jbm.a.31967

Ullah, M., Stich, S., Notter, M., Eucker, J., Sittinger, M., and Ringe, J. (2013). Transdifferentiation of mesenchymal stem cells-derived adipogenic-differentiated cells into osteogenic- or chondrogenic-differentiated cells proceeds via dedifferentiation and have a correlation with cell cycle arresting and driving genes. Differentiation 85, 78-90. doi:10.1016/j.diff.2013.02.001

van Gool, S. A., Emons, J. A. M., Leijten, J. C. H., Decker, E., Sticht, C., van Houwelingen, J. C., et al. (2012). Fetal mesenchymal stromal cells differentiating towards chondrocytes acquire a gene expression profile resembling human growth plate cartilage. PLoS ONE 7:e44561. doi:10.1371/journal. pone. 0044561

Wang, H., Pieper, J., Peters, F., van Blitterswijk, C. A., and Lamme, E. N. (2005). Synthetic scaffold morphology controls human dermal connective tissue formation. J. Biomed. Mater. Res. 74, 523-532. doi:10.1002/jbm.a.30232

Woodfield, T. B. F., Malda, J., de Wijn, J., Peters, F., Riesle, J., and van Blitterswijk, C. A. (2004). Design of porous scaffolds for cartilage tissue engineering using a three-dimensional fiber-deposition technique. Biomaterials 25, 4149-4161. doi:10.1016/j.biomaterials.2003.10.056

Yeatts, A. B., Geibel, E. M., Fears, F. F., and Fisher, J. P. (2012). Human mesenchymal stem cell position within scaffolds influences cell fate during dynamic culture. Biotechnol. Bioeng. 109, 2381-2391. doi:10.1002/bit.24497 
Zaim, M., Karaman, S., Cetin, G., and Isik, S. (2012). Donor age and long-term culture affect differentiation and proliferation of human bone marrow mesenchymal stem cells. Ann. Hematol. 91, 1175-1186. doi:10.1007/s00277-012-1438-x

Zhang, Z. Y., Teoh, S. H., Chong, M. S., Schantz, J. T., Fisk, N. M., Choolani, M. A., et al. (2009a). Superior osteogenic capacity for bone tissue engineering of fetal compared with perinatal and adult mesenchymal stem cells. Stem Cells 27, 126-137. doi:10.1634/stemcells.2008-0456

Zhang, Z. Y., Teoh, S. H., Chong, W. S., Foo, T. T., Chng, Y. C., Choolani, M., et al. (2009b). A biaxial rotating bioreactor for the culture of fetal mesenchymal stem cells for bone tissue engineering. Biomaterials 30, 2694-2704. doi:10.1016/j. biomaterials.2009.01.028
Conflict of Interest Statement: The authors declare that the research was conducted in the absence of any commercial or financial relationships that could be construed as a potential conflict of interest.

Copyright (C) 2015 Leferink, Chng, van Blitterswijk and Moroni. This is an open-access article distributed under the terms of the Creative Commons Attribution License (CC BY). The use, distribution or reproduction in other forums is permitted, provided the original author(s) or licensor are credited and that the original publication in this journal is cited, in accordance with accepted academic practice. No use, distribution or reproduction is permitted which does not comply with these terms. 